\title{
Patient automedication and professional prescription pattern in an urgency service in Brazil
}

Karen Barea DE-PAULA ${ }^{(a)}$ Leonardo Spohr da SILVEIRA(a) Gabriela Xavier FAGUNDES(b) Maria Beatriz Cardoso FERREIRA(c) Francisco MONTAGNER(a)

\footnotetext{
(a) Dental School, Universidade Federal do Rio Grande do Sul - UFRGS, Porto Alegre, RS, Brazil

(b)Dental School, Pontifícia Universidade Católica do Rio Grande do Sul - PUCRS, Porto Alegre, RS, Brazil.

(c)Department of Pharmacology, Institute of Biological Sciences, Universidade Federal do Rio Grande do Sul - UFRSG, Porto Alegre, RS, Brazil.
}

Declaration of Interests: The authors certify that they have no commercial or associative interest that represents a conflict of interest in connection with the manuscript.

\section{Corresponding Author: \\ Francisco Montagner \\ E-mail: francisco.montagner@ufrgs.br}

DOI: 10.1590/1807-3107BOR-2014.vol28.0041 Epub XXX XX, 2014

Submitted: Dec 03, 2013

Accepted for publication: May 06, 2014 Last revision: Aug 06, 2014

\begin{abstract}
Several studies have indicated an increased resistance of microorganisms resulting from the widespread use of antimicrobial agents. However, few data are available in the dental literature. The aim of this study was to conduct a survey on the patterns of patient usage of antimicrobial prescriptions agents by dentists. A retrospective cross-sectional study was based on the medical records of 223 patients who sought treatment at the Urgency Service, from a Dental School in the South of Brazil, from March 2009 to March 2011. A specific data sheet was used, with questions regarding: patient age and gender; the main complaint; medications used prior to the service; final diagnosis; proposed dental treatment (including prescription medications); and characteristics of the final prescription. Descriptive and inferential statistics were obtained. There was a high frequency of antibiotic use prior to attendance by young patients (Fisher's exact test, $\mathrm{p}<0.05$ ). Toothache of endodontic origin was the most frequent patient complaint (72.6\%). Endodontic procedures were the measures most frequently adopted to treat the pain (31.2\%). The frequency of patient use of antimicrobials prior to the appointment was $14.3 \%$. According to patient records, $83.9 \%$ had no systemic drug prescription after receiving urgency treatment. There were few antimicrobial prescriptions after the urgency treatment. The most frequently prescribed agents were amoxicillin, chlorhexidine, and metronidazole. Local measures were more frequently used than systemic approaches to treat urgencies of dental origin. Antimicrobial agents were not frequently prescribed as adjunctives to local administered at the urgency service.
\end{abstract}

Keywords: Pain; Anti-bacterial agents; Drug Resistance; Endodontics.

\section{Introduction}

Dental emergencies are clinical conditions associated with significant discomfort and pain, requiring immediate treatment. They include infectious diseases such as apical or periodontal abscesses and pericoronaritis. It is well-known that the clinical resolution or relief of the signals and symptoms in most cases is performed through local measures associated or not with antimicrobial prescription. ${ }^{1}$ Antimicrobial agents have been the drugs most-prescribed by dentists, especially $\beta$-lactamic agents, macrolides, lincosamides, and tetracyclines. ${ }^{2,3,4}$ These medicaments are indicated in acute odontogenic infections associated with the presence of clinical signs and symptoms of systemic involvement such as fever, lymphadenopathy, prostration, or immunosuppression. Dentists must attempt to identify the 
relationship between the cost and benefits of their prescriptions. The arbitrary prescription of antimicrobials is often adopted by dental professionals, which may favor the emergence of resistant microorganisms. ${ }^{5}$ In some cases, excessive prescription is supported by the lack of both knowledge and confidence on the part of the professional, who believes that 'only local' measures will be unable to control and/or eliminate the infection spread throughout the apical tissues.

The medicament must be effective when prescribed for an adequate period, and must be accessible and available to the patient. The pharmaceutical industry has introduced a broad range of medicaments that can make difficult the professional choice of prescription drugs. ${ }^{6}$ There are criteria that guide the use of antimicrobial agents to favor the rational use of medication. The World Health Organization (WHO) suggests a set of prescribing drug indicators that has been useful to evaluate prescription patterns in health care facilities. They included the number of drugs prescribed at each appointment and the percentage of appointments with at least one antimicrobial agent prescription. For the first indicator, $\mathrm{WHO}$ recommends a limit of two drugs per appointment. WHO does not establish a specific value for the second parameter. ${ }^{7}$ However, Cosendey et al. ${ }^{8}$ suggested a maximum limit of $20 \%$ of prescriptions containing antimicrobial agents for primary care. Prescribing indicators have been used in several studies in the medical area, demonstrating problems in the patterns of medical prescribing in different regions of the world. ${ }^{9,10,11,12}$ Few studies also report similar behavior for the prescription of medicaments in dentistry. ${ }^{2,3,4}$

Therefore, the main objective of the present study was to evaluate the frequency of antimicrobial use by patients prior to presenting to an urgency service and the pattern of prescription of these medicines in the Urgency Service, from a Dental School in the South of Brazil, during a period of two years.

\section{Methodology}

The present transverse retrospective study was approved by the Research Board and by the Ethics Committee in Research (Project number 21480) from the Universidade Federal do Rio Grande do Sul (Porto Alegre, RS, Brazil). The patient records belonging to the Urgency Service Files, from a Dental School in the South of
Brazil, from March 2009 to March 2011 were analyzed. Patients' data reported in the clinical files, such as age, gender, reason for seeking urgency treatment, previously used medicaments, diagnosis, treatment modalities, and prescriptions, were recorded. Files with unclear and uncertain information and files that belonged to patients $<18$ yrs old were excluded from the present study. Sample size was determined with the statistical package Pepi4-DOS. ${ }^{13}$ Parameters were obtained from a pilot study that considered the total number of patients seeking urgent treatment in the Dental School in a period of one year. In that study, the prevalence of previous antimicrobial use by patients was $20 \%$. The significance level was set at $95 \%$, and the maximum acceptable difference was $5 \%$. The sample size required was estimated at a minimum of 170 medical records.

Information was collected and summarized using Epi-Data v1.5 (EpiData Association, Odense, Denmark). Statistical analysis was carried out with SPSS v19.0 for Windows (IBM® SPSS Statistics, New York, USA). Descriptive and inferential statistics were obtained. Results were expressed as absolute or relative frequencies, and means and respective standard deviations (SD), according to data characteristics. Fisher's Exact Test was used to determine association between antimicrobial prescription and the age group of the patients. The significance level was set at $5 \%$.

\section{Results}

In total, 223 records were evaluated. The mean age of the patients was 41 yrs-old (SD $\pm 14,5$ ), and $68.6 \%$ were women. Adult patients (from 18 to 59 yrs old) comprised $89.2 \%(199 / 223)$ of the sample.

One hundred and sixty-two patients (72.6\%) took medicines before seeking urgency care. Analgesics, anti-inflammatories, and antimicrobial agents were the most frequently used groups of medicaments before the appointment, corresponding to $43.8 \%$. Thirty-two patients $(14.3 \%)$ reported taking antimicrobial agents. The five most frequently used agents were acetaminophen (6.2\% of the medicines in use), amoxicillin (18\%), diclofenac (10.4\%), ibuprofen $(9.7 \%)$, and NSAIDs non-specified by patients $(3.5 \%)$. Drugs for the treatment of other systemic diseases were used by $43 \%(n=96)$ of the patients. It should be emphasized that these were not considered as medicaments adopted by the patient to control pain of 
odontogenic origin previous to the urgency treatment. Oral contraceptives (5.4\% of the medicines in use prior to the consult), cardiovascular agents (captopril [4.8\%], hydrochlorothiazide [2.7\%], enalapril [2.1\%], propranolol [2.1\%]), omeprazole (2.1\%), simvastatin (2.1\%), and antidiabetic agents (metformin [1.8\%], insulin [1.5\%], glibenclamide [1.5\%]) were the medicines more frequently reported as in use by the patients.

There was no statistically significant difference between adult and elderly patients for the use of medicines to treat systemic conditions $-71.8 \%$ for adult patients versus $79.1 \%$ in elderly patients (Fisher's Exact Test, $p=0.63$ ). However, there was a significant association between the intake of analgesic, antiinflammatory, or antimicrobial agents and patient age (Fisher's Exact Test, $\mathrm{p}=0.002$ ). Adult patients used these agents more frequently than did the elderly ( $48.92 \%$ versus $8.8 \%$ ). Patients aged $\geq 60$ yrs took only one or two anti-inflammatory/antimicrobial medicaments. In contrast, two adult patients reported the intake of 5 anti-inflammatory/antimicrobial medicaments before seeking urgency treatment. A statistically significant difference was observed for the intake of antimicrobial medicaments before urgency treatment in terms of age group (Fisher's Exact Test, $\mathrm{p} \leq 0.05$ ). Adult patients took antimicrobial agents more frequently than did the elderly.

Toothache of endodontic origin was the most frequent patient complaint (72.6\%). Pain or discomfort associated with periodontal diseases represented $4.5 \%$ of the sample. The frequencies of tooth fractures and loss of a temporary restoration corresponded to $3.6 \%$ and $2.7 \%$ of the cases, respectively. It was observed that $14.3 \%$ of the patients' complaints were inaccurately described, had incomplete information, or were illegible in the urgency record.

The great majority of clinical procedures were performed to control signs/symptoms of endodontic origin (31.6\%). The most common dental procedures performed were coronal access, placement of intracanal medicament, and coronal sealing ( $31.6 \%$ of the cases). Tooth extraction was performed in $11.5 \%$ of cases, temporary or definitive restoration in $9.3 \%$, and caries removal in $8.9 \%$, with other procedures comprising $9.7 \%$ of cases.

According to patient records, $83.9 \%$ had no systemic drugs prescribed after the urgency treatment.
One medicine was prescribed for $8.5 \%$ of the patients, two medicines for $5.8 \%$, and three or more for $1.8 \%$. Polypharmacy was not observed in any prescriptions after the urgency treatment. Sixteen different drugs were prescribed. Antimicrobial agents represented the most frequently prescribed group (57.8\%) (Table 1).

There was no statistically significant difference between the frequency of antimicrobial prescriptions between adult and elderly patients (Fisher's Exact Test, $\mathrm{p}=0.57$ ). Adult patients had $8.5 \%$ of antimicrobial prescription after emergency treatment, while elderly patients had $8.3 \%$. There was no statistically significant difference in the frequency of antimicrobial prescription for male and female patients $(10 \%$ and $7.8 \%$, respectively; Fisher's Exact Test, $\mathrm{p}>0.05$ ).

Table 1. Pharmacological groups and medicaments prescribed after the dental consult in the urgency care.

\begin{tabular}{lc}
\hline Pharmacological groups (\%) & Medicaments (\%) \\
\hline $\begin{array}{l}\text { Antimicrobial agents } \\
(57.8 \%)\end{array}$ & $\begin{array}{c}\text { Amoxicillin (21.1\%), chlorhexidine } \\
(15.8 \%), \text { metronidazol (7.0\%), } \\
\text { unspecified (7.0\%), and other (7.2\%) } \\
\text { antimicrobial agents. }\end{array}$ \\
Analgesics (28.07\%) & $\begin{array}{c}\text { Acetaminophen (21.1\%), unspecified } \\
\text { analgesics (3.5\%), dipyrone (3.5\%) }\end{array}$ \\
$\begin{array}{l}\text { Anti-inflammatory agents } \\
\text { (7.04\%) }\end{array}$ & Ibuprofen (7.04\%) \\
\hline
\end{tabular}

\section{Discussion}

The use of analgesics and antimicrobial agents has been associated with health care cost implications as well as with the potential for the development of drug abuse and microbial resistance. Therefore, the aim of this study was, through a comprehensive analysis of patients' records, to access the frequency of antimicrobial use and prescription patterns for outpatients who had attended the Dental Urgency Service in a Brazilian Dental School for a period of two years. Hocker et al. ${ }^{14}$ and Okuseki et al. ${ }^{1}$ have also used this method to evaluate the medicament usage profiles of patients who attended emergency clinics. These authors pointed out that the sample obtained in some clinical file analyses might be limited by the period of evaluation and by the characteristics of the urgency service. The database analysis 
was comprised only of information provided by the physician/dental surgeon, and was not validated by direct patient information provided to the researchers. Furthermore, the data that led to the decision to us an antimicrobial agent for a specific condition were not precisely obtained from the files. Therefore, it was not possible to determine if the medication was properly prescribed.

The number of medicines per prescription, the frequency of polypharmacy, and the percentage of prescriptions containing at least one antimicrobial agent have been used by World Health Organization (WHO) as indicators of rational use of medicines. Previous studies have shown that these parameters were inadequate in several instances of medical prescription., ${ }^{92,15,16}$ There are few data in the dental literature on drug prescription patterns in dentistry. ${ }^{2,1718}$ In the present study, 93/223 (41.7\%) patients took analgesics/antimicrobial agents before the emergency appointment, and only $36 / 223$ (16\%) received a prescription after the appointment. Patients reported using antimicrobial agents before urgency treatment $(18.7 \%)$. The analysis of the urgency files did not allow for the determination of whether these medicaments had been previously prescribed by a health professional or if there was self-medication. Cheaitot et al. ${ }^{19}$ reported that self-medication with antimicrobial agents is also a relatively frequent problem in the Beirut area, because $42 \%$ of those in the study population bought them directly from pharmacies. The Brazilian government has adopted several measures to ensure the control of antimicrobial agent sales and delivery (ANVISA, 2011). ${ }^{20}$ However, further studies must be conducted to evaluate if the regulatory measures improved the control of medicament consumption in the Brazilian population.

The age group seemed to represent an important factor in terms of the consumption of medicaments. In the present study, adults took analgesics, antiinflammatories, or antimicrobials more frequently than did the elderly before seeking urgency treatment. Napolitano et al. ${ }^{21}$ reported that patients under $40 \mathrm{yrs}$ of age were more inclined to take an antibiotic without prescription than those over age 45 . Therefore, it is important to reinforce education on drug consumption, especially for this group of patients.

The file analysis suggested that amoxicillin, chlorhexidine, and metronidazole were usually recommended as adjunctive measures for the treatment of dental infections, suggesting a rational pattern of prescription. Twenty-four patients had antimicrobial agents after the urgency appointment, and amoxicillin was the first choice for 12/24 (50\%). Amoxicillin and other penicillin derivatives were shown to be highly effective against a wide variety of aerobic and anaerobic bacteria, especially for isolates from acute endodontic infections. ${ }^{22,23}$ Amoxicillin is available in the public health system in Brazil. ${ }^{24}$ Tavares et al. ${ }^{25}$ reported that amoxicillin was also frequently prescribed in family health units in Bagé (Rio Grande do Sul, Brazil). It is important to emphasize that factors such as the prevalence of specific types of pathogens in the community, adequacy of infrastructure in the geographic area analyzed (e.g., water supply, sewage system, and hygiene habits), and accessibility to the health care system may lead to different prevalence of infections and distinct patterns of prescription of antimicrobial agents. ${ }^{26}$

Acetaminophen, diclofenac, and ibuprofen were frequently taken before patients sought urgency treatment. Patients usually associate pain relief with the use of an analgesic/anti-inflammatory medicament. The diagnoses reported in the dental records were compatible with these conditions. In the present study, acetaminophen was frequently prescribed by dental professionals. The prescription mentioned above can be considered adequate because dental procedures are usually associated with the presence of low to moderate postoperative pain. In a study performed in Minas Gerais, Brazil, ${ }^{2} 163$ dentists were interviewed about their prescription patterns for analgesics, anti-inflammatories, and antimicrobial agents. It was observed that dental professionals prescribed anti-inflammatories more frequently than analgesic agents. Authors have also reported that sodium and potassium diclofenac (19.5\% and $39.9 \%$, respectively) were more commonly prescribed than acetaminophen (14.3\%). ${ }^{2}$

Analysis of data collected from the files in the present study showed that $83.9 \%$ of the patients did not take prescription medicaments after clinical procedures. Local treatments are important measures to control pain in dental emergencies. For the great majority of patients, those measures were effective to treat the clinical condition. Pulpitis and acute apical periodontitis were the dental emergencies most often 
detected in the present study. Local measures such as pulp removal or root canal debridement, followed by the placement of an intracanal medicament, were able to control pain of endodontic origin. Systemic medicaments were not determinant measures for the effective control of pain. Therefore, dental professionals should not prescribe medicines without evidence of efficacy and safety, or based on myths or marketing influence.

As a limitation of the present analysis, the pattern of use and prescription of drugs was evaluated in a retrospective study, based on the information described in the urgency records. These files are legal documents frequently used for clinical, legal, and research purposes. However, inaccuracies in patient records have been previously documented. Dar-Odeh et al. ${ }^{17}$ showed that the dentists interviewed in their study tended not to complete forms with fundamental clinical data. Murrah et al. ${ }^{27}$ observed that $17 \%$ of the prescriptions provided by dental professionals were only verbal. In a previous study in Brazil, Castilho et al. ${ }^{2}$ observed that $13 \%$ of dental professionals did not record clinical data for all of their patients, and $43 \%$ of them did not record the drugs prescribed. Therefore, there is a possibility that the frequencies regarding the use and prescription of drugs reported in the present study might be underestimated.

\section{References}

1. Okunseri C, Okunseri E, Thorpe JM, Xiang Q, Szabo A. Medications prescribed in emergency departments for nontraumatic dental condition visits in the United States. Med Care 2012 Jun;50(6):508-12.

2. Castilho LS, Paixão HH, Perini E. Prescrição de medicamentos de uso sistêmico por cirurgiões-dentistas, clínicos gerais. Rev Saude Publica. 1999 Jun;33(3):287-94.

3. Palmer NOA, Martin MV, Pealing R, Ireland RS. An analysis of antibiotic prescriptions from general dental practitioners in England. J Antimicrob Chemother. 2000 Dec;46(6):1033-5.

4. Al-Haroni M, Skaug N. Incidence of antibiotic prescribing in dental practice in Norway and its contribution to national consumption. J Antimicrob Chemother. 2007 Jun;59(6):1161-6.

5. Sweeneyl LC, Davel J, Chambers PA, Heritagel J. Antibiotic resistance in general dental practice-a cause for concern?. J Antimicrob Chemother. 2004 Apr;53:567-76.
Analysis of the data collected from emergency files suggests a rational prescription of medicines by dental professionals. It could be attributed to the place where the study was performed, in a dental emergency service in a public university. However, the data must not be similar to those for other emergency care services. Data reported in the present study are relevant because academic health services were characterized by their important role in the development of future professionals. Heineck et al. ${ }^{28}$ reported that the information acquired during internship programs and in health care routines were the principal source of knowledge for medical professionals in a surgical area in Brazil.

\section{Conclusion}

According to the present retrospective study, antimicrobial agents were not frequently prescribed as adjuncts to local therapies after urgency treatments in dentistry. There was an absence of polypharmacy, and few medicines were indicated for patients at the end of the appointment. Additional studies should be conducted to evaluate the prescription criteria and regimens adopted by dental professionals, as well as patient compliance with the treatment. Furthermore, dental students should be strongly encouraged to complete patient records properly to allow for both studies on treatment planning and outcome.

6. Spurling GK, Mansfield PR, Montgomery BD, Lexchin J, Doust J, Othman N, et al. Information from pharmaceutical companies and the quality, quantity, and cost of physicians' prescribing: a systematic review. PLoS 2010 Oct;7(10):e1000352.

7. World Health Organization. How to investigate drug use in health facilities: selected drug use indicators. Geneva: WHO; 1993.

8. Cosendey MAE, Bermudez JAZ, Reis ALA, Silva HF, Oliveira MA, Luiza VL. Assistência farmacêutica na atenção básica de saúde: a experiência de três estados brasileiros. Cad Saude Publica. 2000 Jan;16(1):171-82.

9. Ferreira MBC, Heineck I, Flores LM, Camargo AL, Dal Pizzol TS, Torres ILS, et al. Rational use of medicines: prescription indicators in different levels of health care. Braz J Pharm Sci. 2013 Apr-Jun;49(2):329-40. 
10. Nikfar S, Kebriaeezadeh A, Majdzadeh R, Abdollahi M. Monitoring of National Drug Policy (NDP) and its standardized indicators; conformity to decisions of the national drug selecting committee in Iran. BMC Int Health Hum Rights. 2005 May;5(1):5.

11. Sharif SI, Al-Shaqra M, Hajjar H, Shamout A, Wess L. Patterns of drug prescribing in a hospital in Dubai, United Arab Emirates. Libyan J Med. 2008 Mar;3(1):10-2.

12. Vallano A, Montané E, Arnau JM, Vidal X, Pallarés C, Coll M, et al. Medical specialty and pattern of medicines prescription. Eur J Clin Pharmacol. 2004 Dec;60(10):725-30.

13. Abramson JH, Peritz E. Calculator programs for the health sciences. NewYork: Oxford University Press; 1983.

14. Hocker MB, Villani JJ, Borawski JB, Evans CS, Nelson SM, Gerardo CJ et al. Dental visits to a North Carolina Emergency Department: a painful problem. N C Med J. 2012 SepOct;73(5):346-51.

15. Colombo D, Helena ETS, Agostinho ACMG, Didjurgeit JSMA. Padrão de prescrição de medicamentos nas unidades de Programa de Saúde da Família de Blumenau. Braz J Pharm Sci. 2004 Oct; $40(4): 549-58$.

16. Santos V, Nitrini SMOO. Prescription and patient-care indicators in healthcare services. Rev Saude Publica. 2004 Dec;38(6):819-26.

17. Dar-Odeh N, Ryalat S, Shayyab M, Abu-Hammad O. Analysis of clinical records of dental patients attending Jordan University Hospital: documentation of drug prescriptions and local anesthetic injections. Ther Clin Risk Manag. 2008 Oct;4(5):1111-7.

18. Palaian S, Shankar PR, Hedge C, Hedge M, Ojha P, Mishra $\mathrm{P}$. Drug utilization pattern in dental outpatients in tertiary care teaching hospital in western Nepal. N Y State Dentd J. 2008 Jan:74(1):63-8.

19. Cheiato L, Azizi S, Saleh N, Salameh P. Assessment of selfmedication in population buying antibiotics in pharmacies: a pilot study from Beirut and its suburbs. Int J Public Health. 2014 Apr;59(2):319-27.
20. Agência Nacional de Vigilância Sanitária (Brasil). Resolução RDC n²0, de 05 de maio de 2011 [Internet]. Diário Oficial da União, 2011 maio 09. [cited 2011 Aug 15].Available in: http:// www.anvisa.gov.br/sngpc/Informe_Tecnico_Procedimentos_RDC_n_20.pdf.

21. Napolitano F, Izzo MT, Di Giuseppe G, Angelillo IF. Public knowledge, attitudes, and experience regarding the use of antibiotics in Italy. PLoS One. 2013 Dec 23;8(12):e84177. doi: 10.1371/journal.pone.0084177. eCollection 2013.

22. Jacinto RC, Montagner F, Signoretti FG, Almeida GC, Gomes BP. Frequency, microbial interactions, and antimicrobial susceptibility of Fusobacterium nucleatum and Fusobacterium necrophorum isolated from primary endodontic infections. J Endod. 2008 Dec;34(12):1451-6.

23. Gomes BP, Jacinto RC, Montagner F, Sousa EL, Ferraz CC. Analysis of the antimicrobial susceptibility of anaerobic bacteria isolated from endodontic infections in Brazil during a period of nine years. J Endod. 2011 Aug;37(8):1058-62.

24. Brasil. Ministério da Saúde. Secretaria de Ciência, Tecnologia e Insumos Estratégicos. Departamento de Assistência Farmacêutica e Insumos Estratégicos. Relação nacional de medicamentos essenciais: Rename. $7^{\mathrm{a}}$ ed. Brasília (DF): Ministério da Saúde; 2010.

25. 25.Tavares NU, Bertldi L, Andréa D, Muccillo-Baisch AL. Prescrição de antimicrobianos em unidades de saúde da família no Sul do Brasil. Cad. Saúde Pública. 2008 Aug;24(8):1791-800.

26. Gavazzi G, Herrmann F, Krause K-H. Aging and infectious diseases in the developing world. Clin Infect Dis. 2004 Jul 1;39(1):83-91.

27. Murrah V, Merry JW, Little JW, Jaspers MT. Compliance with guidelines for management of dental school patients susceptible to infective endocarditis. J Dent Educ. 1987 May;51(5):229-32.

28. Heineck I, Ferreira MBC, Schenkel EP. Antibioticoprofilaxis quirúrgica: práctica de prescripción y nivel de conocimiento. Acta Farm Bonaer. 2000;19(4):295-302. 